\title{
Metadiscourse Markers in Pure Mathematics Textbooks
}

\author{
Hassan Banaruee (Corresponding author) \\ Dept. of Language and Literature, Chabahar Maritime University \\ E-mail: Hassan.banaruee@gmail.com
}

\begin{abstract}
Amir Mohammadian
Dept. of Language and Literature, Chabahar Maritime University

E-mail: amir.mohamadian@cmu.ac.ir
\end{abstract}

Esmail Zare-Behtash

Dept. of Language and Literature, Chabahar Maritime University

E-mail: behtash@cmu.ac.ir

Received: September 2, 2017 Accepted: September 15, 2017 Published: September 25, 2017

doi:10.5296/gjes.v3i2.11796

URL: https://doi.org/10.5296/gjes.v3i2.11796

\begin{abstract}
The aim of this study was to investigate the use of metadiscourse markers in Mathematics textbooks. To achieve this objective, four chapters of A First Course in Abstract Algebra were selected for data collection. The results showed that interactive markers were more frequent than interactional markers. Among interactive markers, transitions were the most frequent. Logical, proof-based relationship among sentences in Mathematics textbooks is suggested to be the main reason behind the high frequency of transition markers. Endophorics and engagement markers existed in high frequency. Wide use of graphs, figures, charts, and tables are one of the main reasons for the presence of endophorics in Mathematics textbooks. Finally, low frequency of self-mentions and evidentials is another characteristic of Mathematics textbooks that distinguishes them from research articles. The study provides material developers effective implications to apply the metadiscoursal aspects of English in textbooks.
\end{abstract}

Keywords: Metadiscourse, Hyland, Interactive markers, Interactional markers 


\section{Introduction}

Academic writing has widely been researched from different aspects in recent years. Features and interactional patterns of academic writing and cross-disciplinary differences are hot topics of discussion among discourse analysts. These studies have demonstrated variations in different disciplines in terms of features characterizing various discourse communities. Hyland (2005a) suggests that writing in every discipline has its own characteristics. Becher and Trowler (2001) and Hyland (2005a) have investigated disciplinary writing and its practices. Hyland (2005b) presented a classification of metadiscourse markers and compared their pattern of use in dissertations in various fields. He concluded that there are wide differences between patterns of use of these markers in various disciplines. According to this model, metadiscourse markers are classified into two categories: interactive and interactional. The writers use interactive markers to guide the readers and interactional markers to involve them in the text. Interactive markers include transitions, frame markers, endophoric markers, evidential, and code glosses. Interactional markers include hedges, boosters, attitude markers, self mentions, and engagement markers. Hyland (2005b) defines stance as the ways writers present themselves and convey their judgments, opinions, and commitments. By adopting a stance, the writers express their personal feelings, attitudes, value judgments, or assessments.

A large body of research has demonstrated that each language uses metadiscourse markers in its own way. Crismore, Markannen, and Steffenson (1993) compared US and Finish students in terms of their use of textual and interpersonal metadiscourse markers and showed the differences between these two cultural groups. Also, other studies have shown that rhetorical features are language-specific. Zhang (1990) points out to the indirectness in Chinese and Tirkonan-condit (1996) claimed that Finish is implicit.

Studying metadiscourse and its function in academic texts has some pedagogical implications. Zare-Behtash and Banaruee (2017) found that textbooks with utilized metadiscourse markers are more assistive and informative. Hyland (2005b) claims an awareness of metadiscourse offers three main advantages. First, it helps students better understand the cognitive demands that text make on readers and the ways writers can assist them to process information. Second, it provides them with the resources to express a stance towards their statements. Third, it allows them to negotiate this stance and engage in a community-appropriate dialogue with readers.

This study aimed to investigate the ways that metadiscourse markers are employed to organize texts of Mathematics textbooks in English. To achieve this objective, Hyland's model of metadisciurse markers was used to obtain the number of various markers in four chapters of a Mathematics textbook.

\section{Review of the Literature}

Numerous studies have investigated the discourse of dissertations, research articles, and textbooks of various disciplines, but research into the discourse of mathematics texts has been limited. Using Hyland's stance and engagement framework, Mc Grath and Kuteeva (2011) studied the discourse of 25 research articles in pure Mathematics. They concluded that in the 
sections outlining the proof, there are a high number of directives and a low number of hedges and also a relatively high number of shared knowledge references. According to Hyland (2005a), this is a characteristic of texts in soft disciplines.

Swales, Ahmad, Chang, Chavez, and Seymour (1998) studied imperatives in research articles in mathematics and concluded that main text imperatives tend to congregate in sections where the principal argumentation occurs. After interviewing of experts of ten disciplines, they reported that despite the potentially face-threatening nature of imperatives, authors use them for strategic purposes such as engaging the reader, achieving text economy, or manifesting personal style. Burton and Morgan (2000) explored the identities that mathematicians present to the world in their writing and the ways in which they represent the nature of mathematical activity. In their study, analysis of 53 published research papers revealed substantial variations in these aspects of mathematicians' writing.

O'Halloran (2005) explored language and symbolism in mathematics discourse. Bakhtin (1981) refers to the discourse of textbooks as 'undialogized' discourse, where we find the accepted theories of a discipline. According to Hyland (2005b), transitions, code glosses, and endophoric markers are more frequent in the textbooks, while those typically used to assist persuasion, such as hedges, boosters, evidential, and self mention are more frequent in the articles.

The goal of this study was to find how metadiscourse markers are employed to organize information in Mathematics textbooks. To achieve this objective, four chapters of A First Course in Abstract Algebra were selected for the collection of data. All metadiscourse markers in these four chapters were identified. In this way, this study tried to answer the following questions:

1). Which metadiscourse markers are more frequent in Mathematics textbooks?

2). Why are some metadiscourse markers more frequent in Mathematics textbooks?

\section{Methodology}

\subsection{Materials}

In this study, four chapters of a book entitled A First Course in Abstract Algebra written by Fraleigh were selected for the collection of data. These four chapters are normally considered the main chapters taught in educational systems. Hyland's (2005) model of metadiscourse markers was used to identify all markers in these four chapters. These markers were counted and recorded in two separate tables, one for interactive markers and another one for interactional markers.

\subsection{Procedure}

After identifying and counting all metadiscourse markers used in four chapters of the book, the number of each marker was recorded. The aim was to find how these markers were used to structure information in mathematics textbooks. Also, a comparison among the numbers of various markers could show which ones were more frequent and which markers play key 
roles in the structuring of information in mathematics textbooks.

\subsection{Data Analysis}

After identifying and counting all metadiscourse markers, the numbers were recorded in two separate tables for interactive and interactional markers. First, a comparison was made between the frequency of interactive and interactional markers. This comparison could show us which one of these two broad categories were used more effectively in Mathematics textbooks. Also, within these two broad categories of markers, some comparisons were made among the frequencies of various subcategories (transitions, frame markers, endophoric markers, evidentials, code glosses, hedges, boosters, attitudes markers, self-mentions, and engagement markers).

\section{Results}

The numbers of interactive and interactional resources that were identified in the data of this study have been given in Table 1 and Table 2.

Table 1. Number of interactive metadiscourse markers

\begin{tabular}{ccccc}
\hline Transitions & Frame markers & Endophoric markers & Evidentials & Code glosses \\
\hline 211 & 27 & 107 & 3 & 28 \\
\hline
\end{tabular}

Table 2. Number of interactional metadiscourse markers

\begin{tabular}{ccccc}
\hline Hedges & Boosters & Attitude markers & Self-mentions & Engagement markers \\
\hline 7 & 23 & 3 & 0 & 69 \\
\hline
\end{tabular}

As can be seen in these two tables, interactive markers, as a general category of markers, are more frequent than interactional markers. Among various interactive markers, transition markers have a significantly higher frequency. Also, the frequency of endophoric markers is substantial. Among interactional markers, engagement markers have the highest frequency. Another interesting observation in these data is the full absence of self-mentions in the data. Also, hedges and attitude markers had a very low presence in the data. A comparison between the frequencies of hedges and boosters show that boosters have a higher presence in Mathematics textbooks.

\section{Discussion}

As was mentioned, transitions had a very high frequency in the data of this study. In Mathematics texts, writers try to present their argument through logical relationships among sentences. In Mathematics, there is no place for guessing and uncertainty. Every statement must be based on a previously-proven statement. In fact, without proof, a statement has no value in Mathematics. This is particularly the case with Abstract Algebra. The focus of 
Abstract Algebra is on a set of abstract concepts. The relations among abstract entities in this field of Mathematics are discussed by statements that are definite. Therefore, logical relationship between each statement and its preceding statement is crucial in this branch of Mathematics. These logical relationships are mainly created by transition markers. For example, when the transition marker 'and' is used between two statements, the meanings of two statements are added together and a complex statement is formed. The meaning of this complex statement is highly dependent on the meaning of both statements.

To take another example, when the transition marker 'but' is used between two statements, some kind of contrast between the two statements is emphasized. In fact, this transition marker is used to show that the second statement is not in line with the first statement. This marker can be used in a variety of situations in which a statement is the opposite of its preceding statement. Also, the transition marker 'therefore' can be used to show that a statement is the logical conclusion of its preceding statement. Like the pervious marker, this marker is very flexible. It can be employed in a variety of situations. This marker might be used to indicate that a situation is the direct result of another situation. Also, it might be used to give a suggestion. These two types of uses have been shown in the following examples:

(a) All elements do not have roots. Therefore, their multiplication has no root.

(b) Using formula 1 will make calculations very complex. Therefore, it would be better to use formula 2.

In all above-discussed examples, we see that logical connections between sentences are extremely important in Mathematics textbooks. Therefore, it would be no surprise to see that transition markers have a very strong presence in these texts.

Endophorics were the second most frequent metadiscourse markers. In Mathematics textbooks, it is very common to use graphs, figures, charts, and tables. Therefore, in a lot of places, writers use endophoric markers to refer to these visual tools. This is particularly the case with textbooks in Abstract Algebra. In this field of Mathematics, we deal with abstract concepts. Since the understanding of these concepts is very difficult by relying only on words, the writers usually use visual tools to facilitate the process of understanding. In fact, these visuals are very powerful tools to represent abstract concepts in an easily-understandable mode. Visual mode is much more understandable than other modes of representation in fields such as mathematics. Perhaps, this feature of Mathematics is the main reason behind the high frequency of endophoric markers in Mathematics textbooks. Writers frequently use endophoric markers to refer to graphs, figures, charts, and tables in the texts. Without using these tools, the understanding of the texts would be very difficult for readers.

Among interactive markers, the low frequency of evidential is another case that needs to be explained. In research articles, the use of evidentials is very common. Writers use evidential markers to refer to the works of other researchers. However, these markers are not frequent in textbooks because in textbooks writers usually talk about established subjects rather than subjects that are currently discussed among researchers. In textbooks, writers do not need to mention the sources and name of people. Therefore, writers rarely use evidential in the 
textbooks. This feature of textbooks is in clear contrast with research articles in which evidentials are widely used to refer to the works of other researchers.

Among interactional markers, engagement markers were the most frequent. However, the frequency of these markers was much lower than the frequency of transition markers and endophorics. Endophoric markers are realized in Mathematics textbooks when writers address the readers and talk to them through the words of the text. This is common technique used in the writing of textbooks. However, it is rarely used in research articles. In fact, in textbooks, the writer directly talks to the readers in order to involve them in the content of the text. Words and small collection of words such as 'consider', 'note', and 'you can see that' are frequently used in textbooks at various levels, including university levels.

Boosters and hedges were not frequent in the texts that were investigated in this study. This is particularly the case with hedges. Since in Mathematics we usually deal with statements that are definite, hedges are rarely used. Hedges are usually used in places where the writer is not sure about something. This rarely happens in Mathematics textbooks. In Mathematics textbooks, writers usually discuss established subjects in which there is no place for uncertainty and disagreement among views.

The final interesting point that was observed in the data of this study was the full absence of self-mentions in the texts. In textbooks of all fields, it is extremely uncommon for writers to refer to themselves in the texts. It is even more uncommon in those textbooks whose content are about field other than humanities. In fields such as Mathematics and Physics, writers discuss subjects which have nothing to do with social issues. Therefore, it is very uncommon for writers to refer to themselves in the texts.

All in all, data gathered in this study indicated that interactive markers were much more frequent than interactional markers. Transactional markers had a significantly higher presence in the texts. Self-mentions, evidential, attitude markers, and hedges were either completely absent or had a very low frequency in the texts.

\section{Conclusion}

Based on the results obtained in this study, it was revealed that interactive markers are significantly more frequent than interactional markers in pure Mathematics textbooks. Among various interactive markers, transitions had a very strong presence in such texts. Strong logical and proof-based relationship among sentences in pure mathematics textbooks was suggested to be the main reason behind the high frequency of transition markers in these textbooks. Endophoric markers had also a high frequency in the textbook that was examined in this study. It was suggested that wide use of graphs, figures, charts, and tables is the main reason for the high frequency of endophoric markers in Mathematics textbooks. Self-mentions, attitude markers, evidential, and hedges had a very low frequency in the textbook that was examined in this study. It seems that very low frequency of evidentials and hedges in textbooks is one of the main characteristics that distinguish this type of texts from research articles. In research articles, writers frequently use evidentials to refer to the works of other researchers. Also, they use hedges to express their uncertainty about issues on which 
researchers do not agree. However, in textbooks, writers usually talk about established subjects and rarely use evidentials and hedges. Such differences between textbooks and research articles must seriously be taken into account in the process of writing academic texts. And this may have some implications material developers to incorporate the metadiscoursal aspects of English in general and those of each discipline in particular into textbooks.

\section{References}

Bakhtian, M. (1981). The Dialogic Imagination. Austin, TX: University of Texas Press.

Becher, T., \& Trowler, P. (2001). Academic tribes and territories. Buckingham:SRHE/Open University Press.

Burton, L., \& Morgan, C. (2000). Mathematicians writing. Journal for Research in Mathematics Education, 31(4), 429-453. https://doi.org/10.2307/749652

Crismore, A., Markannen, R., \& Steffenson, M. (1993). Metadiscourse in persuasive writing: A study of texts written by American and Finnish university students. Written Communication, 10(1), 39-71. https://doi.org/10.1177/0741088393010001002

Hyland, K. (2005a). Stance and engagement: A model of interaction in academic discourse. Discourse Studies, 7(2), 173-192. https://doi.org/10.1177/1461445605050365

Hyland, K. (2005b). Metadiscourse. London: Continuum.

McGrath, L., \& Kuteeva, M. (2011). Stance and engagement in pure mathematics research articles: Linking discourse features to disciplinary practices. English for Specific Purposes, 31(4), 161-173.

O’Halloran, K. (2005). Mathematical discourse: Language, symbolism and visual images. London: Continuum.

Swales, J., Ahmad, U., Chang, Y., Chavez, D., \& Seymour, R. (1998). Consider this: The role of imperatives in scholarly writing. Applied Linguistics, 19(1), 97-121. https://doi.org/10.1093/applin/19.1.97

Tirkkonan-condit, S. (1996). Explicitness vs. implicitness of argumentation: an intercultural comparison. Mutilingua, 15, 274-5. https://doi.org/10.1515/mult.1996.15.3.257

Zare-Behtash, E., \& Banaruee, H. (2017). Critical Evaluation of the New Headway Advanced and the ILI Advanced Series: A Comparison of Curricular Components and CLT Objectives Based on ACTFL. International Journal of Applied Linguistics \& English Literature. https://doi.org/10.7575/aiac.ijalel.v.6n.5p.182

Zhang, J. (1990). Ranking of indirectness in professional writing. Journal of Technical Writing and Communication, 20(3), 291-305. https://doi.org/10.2190/8UR2-F7HM-52CK-U6F8 


\section{Copyright Disclaimer}

Copyright for this article is retained by the author(s), with first publication rights granted to the journal.

This is an open-access article distributed under the terms and conditions of the Creative Commons Attribution license (http://creativecommons.org/licenses/by/3.0/). 